\title{
Effect of Contact Time of Rice Husk Ash and Poly Aluminum Chloride to Reduce the Concentration of Rhodamin B Dyes Using the Adsorption- Fluidization Method
}

\section{Pengaruh Waktu Kontak Abu Sekam Padi dan Poly Aluminium Chloride untuk Menurunkan Konsentrasi Zat Warna Rhodamin B dengan Metode Adsorpsi- Fluidisasi}

\author{
Agung Sugiharto a,1,*, Imam Hoyali a,2, Ahmad Fadli Arya Ghifari ${ }^{a, 3}$, Tasya Hudani Nabilla a,4 \\ ${ }^{a}$ Program Studi Teknik Kimia, Fakultas Teknik, Universitas Muhammadiyah Surakarta, Jl. A. Yani, Mendungan, Pabelan, Kec. Kartasura, Kabupaten \\ Sukoharjo, Jawa Tengah, 57162. Indonesia \\ ${ }^{1}$ agung.sugiharto@ ums.ac.id*; ${ }^{2}$ imamhoyali17@gmail.com; ${ }^{3}$ aryaafag1@gmail.com; ${ }^{4}$ tasyanabilla503@gmail.com \\ * corresponding author
}

ARTICLE INFO

Article history

Received April 29, 2020

Revised July 02,2020

Accepted July 05, 2020

Keywords

Adsorption

Langmuir

Poly Aluminium Chloride

Rhodamin B

Rice husk

\section{ABSTRACT}

The disposal of rhodamine $\mathrm{B}$ of industrial wastewater into the environment without treatment causing water pollution. The purpose of this study is to utilize rice husks as activated carbon which is used to treat industrial wastewater through the adsorption - fluidization process. Also, to determine the effect of variations in contact time on the adsorption process. Carbon from rice husk is activated used $36 \% \mathrm{HCl}$. The adsorption process used activated carbon is variated in contact time for $0,30,60,90,120$, and 150 minutes. Based on the result of this research, the optimal contact time is 120 minutes. At that time, activated carbon from rice husk can reduce initial levels of $50 \mathrm{ppm}$ to $1.142 \mathrm{ppm}$.

This is an open access article under the CC-BY-SA license.

\section{Pendahuluan}

Limbah industri bertambah seiring perkembangan industri saat ini, baik volume dan jenis limbah, khususnya industri tekstil merupakan salah satu penyebab masalah lingkungan akibat limbah buangannya. Masalah yang paling mengganggu dari limbah industri tekstil adalah kandungan zat warna [1]. Pewarna sintetis merupakan penyumbang utama polutan air. Air dengan jumlah besar dapat digunakan untuk tujuan yang produktif tetapi justru terbuang sia-sia [2]. Salah satu zat warna yang sering digunakan pada industri tekstil adalah Rhodamin B. Rhodamin B adalah zat warna berbentuk serbuk kristal, berwarna merah atau ungu kemerahan, tidak berbau, dan dalam larutan berwarna merah terang berfluorensi. Rhodamin B awalnya digunakan untuk kegiatan histologi dan sekarang berkembang untuk berbagai keperluan seperti sebagai pewarna kertas dan tekstil. Pewarna ini terbuat dari dietillaminophenol dan phatalic anchidria dimana kedua bahan baku ini sangat toksik bagi manusia. Pewarna ini sering digunakan untuk pewarna kertas, wol, dan sutra [3].

Salah satu metode untuk menurunkan konsentrasi zat warna adalah adsorpsi. Telah terbukti bahwa adsorpsi (adsorben karbon aktif) merupakan salah satu metode yang paling efektif untuk menghilangkan warna, bau, minyak, dan polutan organik toksik dari proses pengolahan limbah [4]. Adsorpsi merupakan teknologi yang lebih unggul daripada teknik pengolahan air limbah lain dalam hal biaya, fleksibilitas desain, kemudahan operasi, dan ketidakpekaan terhadap polutan beracun sehingga adsorpsi tidak mengakibatkan pembentukan zat berbahaya. Adsorbet yang digunakan dalam proses adsorbsi dapat berbahan alami, biosorben, limbah pertanian, perkebunan, dan industri [5]. Kelemahan pada metode adsorpsi yaitu prosesnya mahal (jumlah karbon atau lumpur aktif yang dibutuhkan banyak) sehingga menimbulkan gagasan untuk membuat metode baru pengolahan 
limbah tekstil menjadi lebih efisien dan efektif. Fluidisasi adalah proses perubahan butiran padat menjadi keadaan seperti fluida (zat alir) dengan cara disuspensikan ke dalam aliran gas atau cairan [4]. Dengan metode ini diharapkan butiran-butiran padat memiliki sifat seperti fluida dengan viskositas tinggi. Pada keadaan ini masing-masing butiran akan terpisahkan satu sama lain sehingga dapat bergerak lebih mudah [6].

Salah satu adsorben yang menjanjikan adalah limbah organik seperti limbah tanaman jagung, padi, pisang, dan lain-lain. Diantara limbah organik tersebut yang menarik untuk digunakan adalah sekam padi. Sekam padi merupakan hasil samping dari proses penggilingan padi. Pemanfaatan sekam padi sangat penting untuk menjaga lingkungan (Pupuk organik, silika gel, bahan bakar alternatif) [1]. Dalam sebuah penelitian dijelaskan sekam padi merupakan bahan berlignoselulosa seperti biomassa lainnya namun mengandung silika yang tinggi. Kandungan kimia sekam padi terdiri atas 50\% selulosa, 25-30\% lignin, dan 15-20\% silika. Sekam padi saat ini telah dikembangkan sebagai bahan baku untuk menghasilkan abu yang dikenal di dunia sebagai rice husk ash (RHA). Abu sekam padi yang dihasilkan dari pembakaran sekam padi pada suhu $400-600{ }^{\circ} \mathrm{C}$ akan menjadi silika amorf. Hasil pengabuan pada suhu $600{ }^{\circ} \mathrm{C}$ selama 2 jam didapat silika sebanyak $72,28 \%$ [7].

Poly Alumunium Chloride (PAC) merupakan salah satu pengganti alum padat yang efektif karena menghasilkan koagulasi air dengan kekeruhan yang berbeda dengan cepat, menggenerasi lumpur lebih sedikit, meninggalkan lebih sedikit residu alumunium pada air yang diolah dan merupakan salah satu koagulan polimer utama yang digunakan secara luas pada pengolahan air dan air limbah $[8,9]$. Koagulan dengan menggunakan PAC telah menunjukkan perubahan warna, COD, dan ammonia yang lebih baik daripada tawas [9]. Penelitian ini bertujuan untuk mengetahui pengaruh waktu kontak abu sekam padi dan PAC terhadap penurunan zat warna Rhodamin B.

\section{Metodologi Penelitian}

\subsection{Alat dan Bahan}

Alat-alat yang digunakan pada penelitian ini antara lain, aerator, beaker glass, labu ukur, muffle furnace, ayakan 60 mesh, dan alat fluidisasi. Sedangkan bahan-bahan yang digunakan dalam penelitian ini adalah karbon aktif sekam padi, PAC, larutan $\mathrm{HCl}$ sebagai aktivator karbon, Rhodamin B digunakan sebagai limbah simulasi. UV/Vis spektrofotometer digunakan untuk menganalisa konsentrasi Rhodamin B per satuan waktu.

\subsection{Pembuatan Karbon Aktif Sekam Padi}

Sekam padi yang telah bersih dan kering dikarbonisasi menggunakan furnace pada suhu $400{ }^{\circ} \mathrm{C}$ selama 2 jam. Karbon yang terbentuk didinginkan, digerus, dan diayak dengan ayakan 60 mesh. Serbuk karbon diaktivasi dengan cara direndam dalam larutan $\mathrm{HCl} 4 \mathrm{~N}$ selama 24 jam. Karbon yang telah diaktivasi dicuci menggunakan aquadest hingga $\mathrm{pH}$ netral dan dikeringkan dalam oven pada suhu $105^{\circ} \mathrm{C}$ selama 3 jam.

\subsection{Proses Adsorpsi}

Sebanyak $600 \mathrm{ml}$ larutan Rhodamin B dengan konsentrasi 50 ppm disiapkan dalam alat fluidisasi dengan kapasitas $600 \mathrm{ml}$. Selanjutnya adsorben sekam padi dan PAC dengan perbandingan 3:1 gram dimasukkan ke dalam alat fluidisasi yang telah berisi larutan Rhodamin B. Kemudian sampel diambil tiap selang waktu tertentu selama 2,5 jam. Selanjutnya konsentrasi Rhodamin B dianalisis dengan Spektrofotometer UV-Vis (Shimadzu) pada panjang gelombang $550 \mathrm{~nm}$.

\subsection{Metode Analisis}

Data hasil adsorpsi dianalisis menggunakan spektrofotometer UV-Vis (Shimadzu) dengan panjang gelombang $550 \mathrm{~nm}$. Data hasil analisis tersebut digunakan untuk perhitungan konsentrasi Rhodamin B dalam cairan dengan rumus:

$$
\mathrm{M}_{1} \cdot \mathrm{V}_{1}=\mathrm{M}_{2} \cdot \mathrm{V}_{2}
$$

Untuk menentukan perhitungan efisiensi digunakan rumus:

$$
\mathrm{E}=\frac{\tau_{0}-\tau_{1}}{\tau_{0}} \times 100
$$


Dimana $\mathrm{T}_{0}$ adalah konsentrasi mula -mula dan $\mathrm{T}_{1}$ adalah konsentrasi setimbang.

\section{Hasil dan Pembahasan}

\subsection{Analisis Kadar Rhodamin B}

Berdasarkan penelitian yang telah dilakukan oleh Puspita [11] tentang pemanfaatan zeolit dari abu sekam padi dengan aktivasi asam untuk penurunan kesadahan air didapatkan hasil bahwa pada saat awal adsorpsi antara waktu kontak 0 menit hingga 20 menit, menunjukkan adanya peningkatan kemampuan adsorpsi yang sangat cepat. Hal ini disebabkan karena pada awal adsorpsi hingga mencapai waktu 20 menit kondisi permukaan adsorben yang masih bersih sehingga menyebabkan proses adsorpsi berlangsung sangat cepat. Proses adsorpsi setelah mencapai waktu kontak 60 menit yaitu pada waktu kontak 90 menit hingga 120 menit mengalami penurunan kemampuan adsorpsi yang ditandai dengan berat $\mathrm{Ca}^{2+}$ dan $\mathrm{Mg}^{2+}$ yang terserap semakin sedikit pada waktu kontak 120 menit. Namun pada saat mencapai waktu kontak optimum (60 menit) terjadi penurunan penyerapan ion logam $\mathrm{Ca}^{2+}$ dan $\mathrm{Mg}^{2+}$ yang disebabkan interaksi ion logam dengan zeolit telah lewat jenuh dimana ion logam $\mathrm{Ca}^{2+}$ dan $\mathrm{Mg}^{2+}$ yang teradsorpsi oleh zeolit yang diaktivasi dengan $\mathrm{HCl}$ terlalu lama sehingga menyebabkan proses adsorpsi terhenti.

Waktu kontak merupakan salah satu dari faktor yang mempengaruhi proses adsorpsi. Semakin lama waktu adsorpsi maka semakin banyak zat warna yang terserap oleh adsorben, akan tetapi apabila waktu kontak terlalu lama akan menyebabkan permukaan yang kosong akan semakin berkurang sehingga kemampuan adsorben untuk menyerap molekul zat warna menurun.

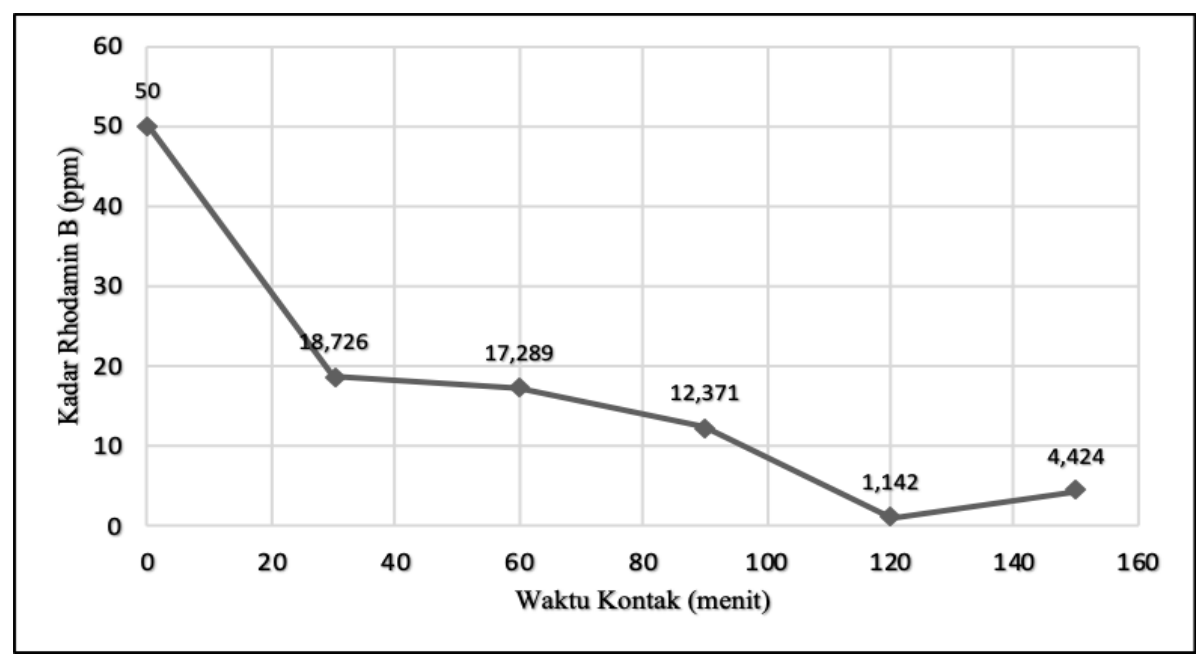

Gambar 1. Hasil Pengujian Rhodamin B

Arang selain digunakan sebagai bahan bakar juga dapat digunakan sebagai adsorben (penyerap). Daya serap dari arang aktif dapat ditentukan oleh luas permukaan partikel. Daya penyerapan dari arang aktif menjadi lebih besar jika arang tersebut dilakukan aktivasi dengan bahan-bahan kimia atau pemanasan pada temperatur tinggi. Bahan kimia yang dapat digunakan untuk aktivasi arang aktif ini dapat berupa $\mathrm{H}_{2} \mathrm{SO}_{4}, \mathrm{HCl}, \mathrm{H}_{3} \mathrm{PO}_{4}$, dan $\mathrm{ZnCl}_{2}$. Karbon yang telah teraktivasi didehidrasi dengan oven bersuhu $105^{\circ} \mathrm{C}$ selama 24 jam $[11,13]$

Waktu kontak optimum terjadi pada waktu 120 menit dengan penurunan menjadi 1,142 ppm dan efisiensi menjadi $97,716 \%$. Pada awal adsorpsi laju berlangsung cepat karena seluruh permukaan pori masih kosong dan molekul zat warna akan menempel dan membentuk suatu lapisan pada permukaan. Namun setelah waktu kontak semakin lama yaitu pada waktu 150 menit permukaan yang kosong akan semakin berkurang sehingga kemampuan adsorben untuk menyerap molekul zat warna menurun, bersamaan dengan ini laju pelepasan kembali molekul zat warna justru meningkat hingga mencapai suatu kesetimbangan. Dengan kata lain, pada kondisi ini proses adsorpsi dan desorpsi adalah sama. Pada saat mencapai titik kesetimbangan, permukaan adsorben telah penuh tertutupi oleh zat warna yang diserap dan adsorben mengalami titik jenuh sehingga adsorben tidak dapat menyerap zat warna lagi [11]. Hal itulah yang mendasari mengapa waktu kontak sangat berpengaruh terhadap proses adsorpsi. 


\subsection{Persamaan Langmuir}

Hubungan antara adsorben dan adsorbat dalam kesetimbangan dijelaskan dalam persamaan isotermis [12]. Persamaan Langmuir menganggap bahwa adsorpsi terjadi pada suatu permukaan yang berisi sejumlah tempat adsorpsi tak terbatas. Proses ini dikenal dengan adsorpsi homogeny, dimana panas konstan dan penyerapan energi aktivasi diekstrak dari masing-masing molekul. Pada pembuatan grafik untuk persamaan Langmuir maka harus diketahui nilai dari adsorbat (zat terserap) oleh adsorben (zat penyerap) $(\mathrm{x} / \mathrm{m}), \mathrm{Ce} /(\mathrm{x} / \mathrm{m})$. Dari grafik yang telah dibuat akan diketahui besar nilai determinasi $\left(\mathrm{R}^{2}\right)$, dimana apabila nilai determinasi semakin besar (mendekati 1), maka prediksi yang dibuat dianggap cukup akurat [14].

Bentuk linier dari model isotherm Langmuir dapat dinyatakan sebagai:

$$
\frac{C e}{C m}=\frac{1}{b C m \text { maks }}+\left(\frac{1}{C m \text { maks }}\right) C e
$$

Dimana

$\begin{array}{ll}\mathrm{Ce} & : \text { Konsentrasi kesetimbangan dari adsorbat }(\mathrm{mg} / \mathrm{L}) \\ \mathrm{b} & : \text { Konstanta Langmuir } \\ \mathrm{Cm}_{\text {maks }} & \text { : Daya adsorpsi }\end{array}$

Tabel 1. Hasil Perhitungan Persamaan Langmuir

\begin{tabular}{ccccc}
\hline $\begin{array}{c}\text { Waktu Kontak } \\
\text { (menit) }\end{array}$ & ce & co-ce & $\mathbf{x} / \mathbf{m}$ & $\mathbf{c e / ( \mathbf { x } / \mathbf { m } )}$ \\
\hline 0 & 50 & 0 & 0 & 0 \\
30 & 18,726 & 31,274 & 0,46911 & 39,9181 \\
60 & 17,289 & 32,711 & 0,490665 & 35,2359 \\
90 & 12,371 & 37,629 & 0,564435 & 21,9175 \\
120 & 1,142 & 48,858 & 0,73287 & 1,5583 \\
150 & 4,424 & 45,576 & 0,68364 & 6,4712 \\
\hline
\end{tabular}

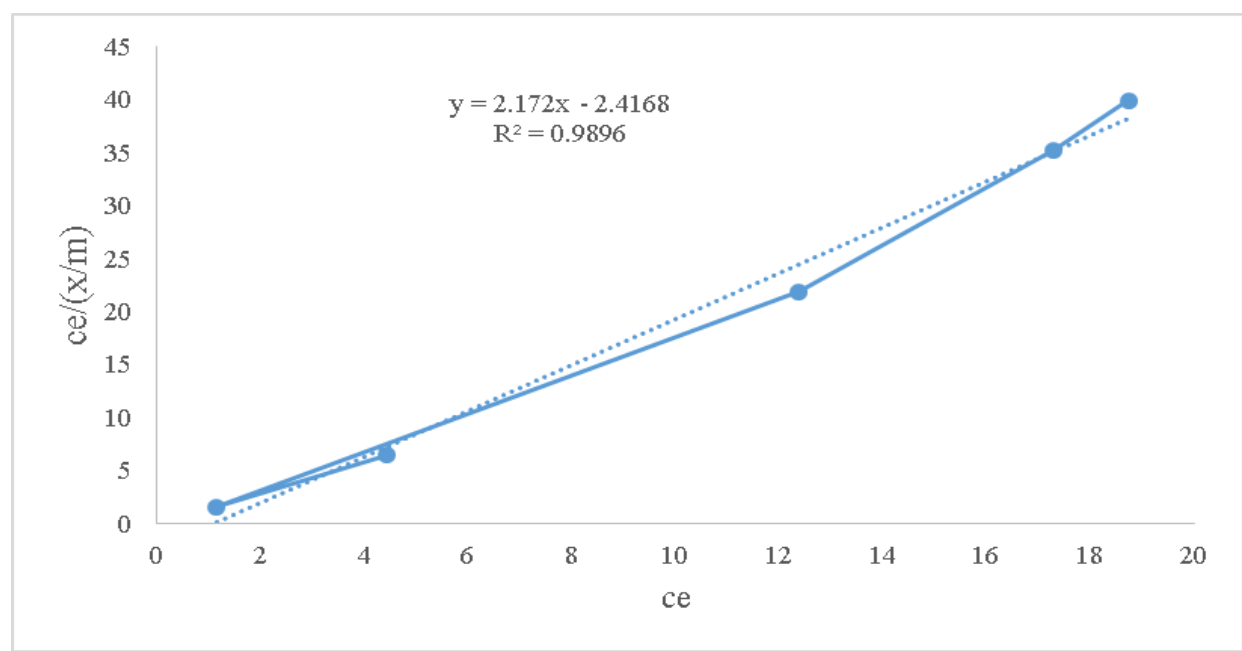

Gambar 2. Hasil Perhitungan Persamaan Langmuir

Hasil yang diperoleh dari variasi waktu kontak dapat digunakan untuk mencari persamaan Langmuir. Didapatkan persamaan $\mathrm{Y}=2,172 \mathrm{x}-2,4168$ dengan $\mathrm{R}^{2}=0,9896$. Dimana ax $: 1 / \mathrm{Cm}_{\text {maks }}$. $\mathrm{Ce}$ dan b : $1 / \mathrm{b} \mathrm{Cm}_{\text {maks. }}$. Dari persamaan tersebut didapatkan nilai $\mathrm{Cm}_{\text {maks }}$ (kapasitas maksimum adsorpsi) sebesar 0,4604 mg/gram dan nilai b (konstanta Langmuir) sebesar 0,8987 L/mg. Dengan nilai $\mathrm{R}^{2}=0,9896$ maka hal ini menunjukkan bahwa persamaan Langmuir dapat diterapkan pada proses adsorpsi Rhodamin B dengan karbon aktif sekam padi. Pendekatan Langmuir meliputi lima asumsi mutlak, yaitu gas yang teradsorpsi berkelakuan ideal dalam fasa uap, gas yang teradsorpsi dibatasi sampai lapisan monolayer, permukaan adsorbat homogeny, artinya afinitas setiap kedudukan ikatan untuk molekul gas sama, tidak ada interaksi lateral antara molekul adsorbat, molekul gas yang teradsorpsi terlokalisasi, artinya mereka tidak bergerak pada permukaan [15]. 


\section{Kesimpulan}

Berdasarkan penelitian yang telah dilakukan dapat disimpulkan bahwa adsorben karbon aktif sekam padi sangat efektif diaplikasikan untuk penjerapan limbah zat warna. Adsorpsi Rhodamin B meningkat dengan naiknya waktu kontak dimana didapatkan waktu kontak optimum pada waktu 120 menit dengan kadar penurunan sebesar 1,142 ppm dengan persentase 97,716\%. Didapatkan kapasitas adsorpsi maksimum sebesar 0,4604 mg/gram, nilai konstanta Langmuir sebesar 0,8987 $\mathrm{L} / \mathrm{mg}$, dan nilai $\mathrm{R}^{2}$ sebesar 0,9896 .

\section{Daftar Pustaka}

[1] Hakim, L. N., A, S., \& Hamzani, S. (2016). Efektifitas Abu Sekam Padi dan Poly Aluminium Chloride Dalam Menurunkan Zat Warna Limbah Cair Industri Sasirangan. Jurnal Kesehatan Lingkungan, 13(2), 346-354.

[2] Khamparia, S., \& Jaspal, D. K. (2017). Adsorption in Combination With Ozonation for the Treatment of Textile Waste Water: a Critical Review. Frontiers of Environmental Science and Engineering, 11(1), 118.

[3] Dianggoni, I., Saputra, E., \& Pinem, J. A. (2017). Pengolahan Zat Warna Tekstil (Rhodamine B) Dengan Teknologi AOP (Advance Oxidation Processes) Menggunakan Katalis Ce@ Carbon Sphere dan Oksidan Peroxymonosulfate. Jom Fteknik, 4(2), 1-7.

[4] Herawati, D., Santoso, S. D., \& Amalina, I. (2018). Kondisi Optimum Adsorpsi-Fluidisasi Zat Warna Limbah Tekstil Menggunakan Adsorben Jantung Pisang. Jurnal Sain Health, 2(1), 1-7.

[5] Suryawan, I. W. K., Afifah, A. S., \& Prajati, G. (2018). Adsorbsi Warna Metylen Blue Menggunakan Powder dan Granular Activated Carbon Biji Binjai (Mangifera Caesia). Jurnal Teknologi Rekayasa, 3(2), 211-218.

[6] Syahrul, S., Romdhani, R., \& Mirmanto, M. (2016). Pengaruh variasi kecepatan udara dan massa bahan terhadap waktu pengeringan jagung pada alat fluidized bed. Dinamika Teknik Mesin, 6(2), 119-126. https://doi.org/10.29303/d.v6i2.15

[7] Safitri, D. I., Tuslinah, L., \& Zustika, D. S. (2019). Pemanfaatan Sekam Padi Sebagai Adsorben Pada Air Laut Dan Zat Warna. 1(2), 1-9.

[8] Murwanto, B. (2018). Efektivitas Jenis Koagulan Poly Aluminium Chloride Menurut Variansi Dosis dan Waktu Pengadukan terhadap Penurunan Parameter Limbah Cair Industri Tahu. Jurnal Kesehatan, 9(1), 143-153.

[9] Mayasari, R., \& Hastarina, M. (2018). Optimalisasi Dosis Koagulan Aluminium Sulfat Dan Poli Aluminium Klorida (PAC) ( Studi Kasus PDAM Tirta Musi Palembang ). 3(2), 28-36.

[10] Aziz, H. A., Daud, Z., Adlan, M. N., \& Hung, Y. T. (2009). The Use of polyaluminium Chloride for Removing Colour, COD and Ammonia From Semi-Aerobic Leachate. International Journal of Environmental Engineering, 1(1), 20-35.

[11]Puspita, M., Firdaus, M. Lu., \& Nurhamidah. (2017). Pemanfaatan Arang Aktif Sabut Kelapa Sawit Sebagai Adsoben Zat Warna Sintetis Reactive Red-120 Dan Direct Green -26. Jurnal Pendidikan Dan Ilmu Kimia, 1(1), 75-79.

[12] Sagala, G., Samudro, G., \& Handayani, D. S. (2013). Studi Perbandingan Adsorpsi Timbal (Pb2+) Pada Media Adsorben Sekam Padi, Jerami, dan Serabut Kayu Meranti. Jurnal ADSORPSI, 1-8.

[13]Habeeb, O. A., Kanthasamy, R., Abdelgawad, G., Ali, M., Yunus, R. B. M., \& Olalere, O. A. (2017). Kinetic , Isotherm and Equilibrium Study of Adsorption of Hydrogen Sulfide From Wastewater Using Modified Eggshells. Journal IIUM Engineering, 18(1), 13-25.

[14] Indihani, R. R., Nugroho, W. A., \& Lutfi, M. (2017). Pengaruh Konsentrasi Aktivator Arang Aktif dan Waktu Kontak Limbah Terhadap Kandungan TDS dan Zat Warna Limbah Cair Batik. Jurnal Keteknikan Pertanian Tropis Dan Biosistem, 5(3), 281-288.

[15] Handayani, M., Sulistiyono E. (2009). Uji Langmuir dan Freudlich Pada Penyerapan Limbah Chrom (VI) Oleh Zeolit. Prosiding Seminar Nasional Sains dan Teknologi Nuklir, PTNBR-BATAN Bandung. 